\title{
Nodular periorbital dirofilariasis in a child in Romania: case report
}

\begin{abstract}
The Dirofilaria repens infection is now recognised as a worldwide emerging parasitic zoonosis, with rare reported human cases in Romania. Herein the clinico-diagnosis features of the nodular periorbital dirofilariasis case in a child are portrayed. This case emphasizes that dirofilariasis should be included in the differential diagnosis of the human nodular disorders at any age and the growing concern from the public health outlook.
\end{abstract}

Keywords: human dirofilariasis, diagnosis, public health
Volume 9 Issue 6 - 2021

\author{
Lidia Lazar, ${ }^{1,2}$ Alexandru Popescu ${ }^{1,3}$ \\ 'University of Medicine \& Pharmacy "Carol Davila", Romania \\ ${ }^{2}$ Colentina Hospital-Parasitic Diseases Department, Romania \\ ${ }^{3}$ Floreasca Emergency Hospital-Surgery Department, Romania
}

\section{Correspondence: Lidia Lazar, University of Medicine \& Pharmacy "Carol Davila”, Bucharest, Romania,}

Tel +40-2I-3 I73245, Email lydia.lazar@yahoo.com

Received: December 07, 202I | Published: December 24 2021

\section{Introduction}

Dirofilariasis is a recognised worldwide emerging parasitic disease, being endemic in many countries of Europe, with rare human infection reported cases in Romania, despite it's high and increasing prevalence in dogs. Nematodes Dirofilaria spp. usually live in canids and felines, in man's body the worms remain in difficulty with a large range of affected organs, most frecquently skin, eye and lungs. We present here a case of periorbital subcutaneous dirofilariasis in a 11 year-old boy from Bucharest. The aim of this article is to draw attention to clinicians about differential diagnosis of the nodular disorders and to public health surveyers concerning the current dynamics of these zoonotic parasitic infections.

\section{Case report}

In mid-March 2018, MC, a 11 year-old boy from Bucharest has been refferred to surgery department of Floreasca Emergency Universitary Hospital, Bucharest for a right periorbital lump. He had no visual or systemic complains, only a local tenderness and a mild paresthesia of the right hemiface were noticed. There was no history of allergy or injuries. Local examination revealed an aproximately $3 \mathrm{~cm}$ diameter of a non-painful, mild itchy and inflammated mobile nodule without loco-regional lymphadenopaty. The lesion has been first noticed as a round, red papule within 6 weeks ago. The boy has spent school winter vacancies to his grandparents home in LehliuCalarasi area, at $64 \mathrm{~km}$ far from Bucharest (Figure 1). No personal pets were owned, but a repeated contact of the child with stray dogs and cats was recognised.

At admission, the complete blood cell count was normal, without eosinophilia. The nodule was surgically removed under local anesthesia, with a surprinsing inside outcome: a living and coiled roundworm emerged intact from lesion. The worm was sent to Colentina Hospital-Parasitic Diseases Department for identification and the patient for medical assessment. Nematod was introduced in a $70 \%$ ethylen alcool solution with $5 \%$ glycerin, being macro and microscopically examined (Figure 2).

\section{The worm}

The worm was white, thin and round, measuring about $10.5 \mathrm{~cm}$ in length and $0.5 \mathrm{~mm}$ in its maximum diameter. The both ends were slender. Microscopically, the anterior extremity was blunty rounded and larger than the posterior one (Figure 3 ). The thick cuticule-outer layer of filaria worm showed well-definite longitudinal ridges with fine transversal striations. The genital pore was identified at aproximately 1 $\mathrm{cm}$ from the anterior end. These features have suggested the presence of an immature female of Dirofilaria repens Railliet \& Henry, 1911 (subgenus Nochtiella).

\section{The patient: postsurgical events}

An additional specific investigations have been completed to the Parasitic Diseases Department- Colentina Hospital, including blood smear, Toxocara spp and Trichinella spiralis ELISA serology tests and general immunogram, including Ig E. No microfilaremia were detected in his blood either anti Toxocara/Trichinella antibodies. A raised value of total $\mathrm{IgG}$ was present $(2788 \mathrm{mg} / \mathrm{dL}, \mathrm{n}=700-1600$ $\mathrm{mg} / \mathrm{dL}$ ), with normal values for other classes of Ig. No systemic antiparasitic treatment was prescribed to patient, the local and general evolution being uneventfully.

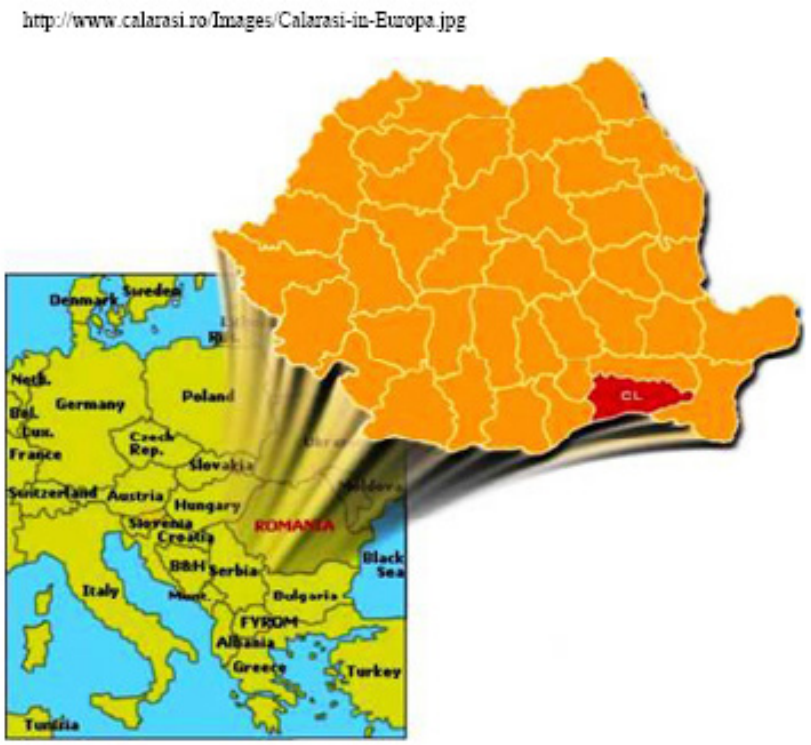

Figure I Local map of suspected area of transmission. 


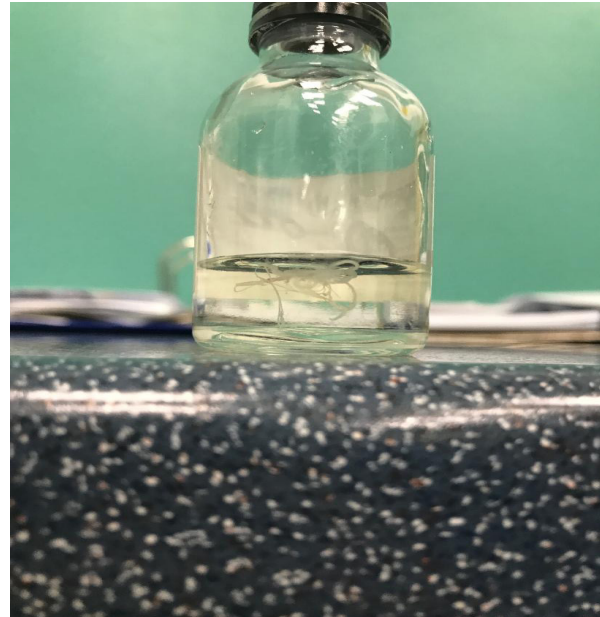

Figure 2 Clinical case: the intact imature worm.

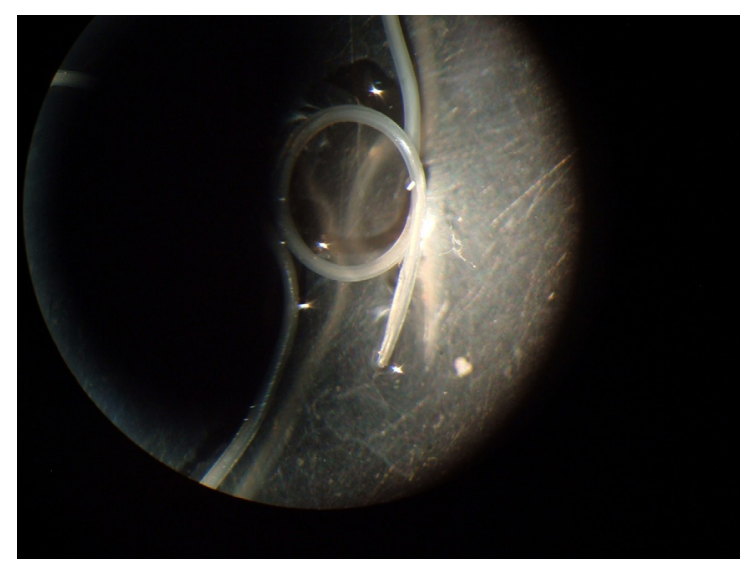

Figure 3 Microscopy of anterior and posterior ends.

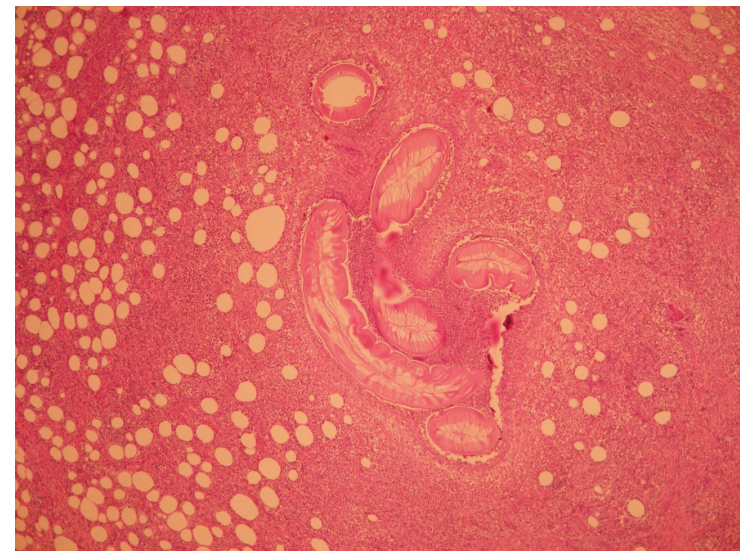

Figure 4 D. repens histologic section-HE stain.

\section{Discusssion}

In 1903 V Babes, first reported animal dirofilariasis in Romania, followed by C Motas and Popovici in 1916. ${ }^{1}$ In 1935 Fr.Popescu has studied the spread of disease in dog population with a prevalence of $65.51 \%$ in the southern counties of the country. ${ }^{1}$ Olteanu has made a general review of dirofilariasis in Romania for the period of 19561995 with a general prevalence of $35 \%$ dirofilariasis in the stray dogs: among 1640 dogs a prevalence of $4,3 \%$ D.immitis and $1.34 \%$ D.repens, respectively were recorded. ${ }^{2}$
Human Romanian cases were sporadically and much later reported by other authors (Gherman, 1990, Voiculescu, 1996, ${ }^{3}$ recently I. Popescu, ${ }^{4}$ 2012, Arbune, $2015^{5}$ ), including other filarial worms with dog or horse origin such as Setaria labiatopapillosa (Panaitescu, 1999). ${ }^{6}$

Dirofilariasis is now recognised as a worldwide- emerging parasitic zoonosis. The most important risk factor is the increasing population of mosquitos due to climate change with milder winters associated with highly infected dogs as main reservoir. In our case there are neither epidemiologic data on infection prevalence in local dogs, or entomological ones concerning the identifiction of mosquito vectors involved in transmission of D.repens in the considered areas (Bucharest, Lehliu). However, a prevalence study of canine populations conducted in 2015 by Ionica et all has disclosed the highest value (18.8\%) in the Romanian southeast counties. ${ }^{7}$

The 2018 winter was an unusual mild season for this region, which geographically belongs to Romanian Plain. The area is located on southeastern side of Romania onto Danube left bank, neighborhood Bulgaria. The climate is temperate continental, with a $500-540 \mathrm{~mm}$ average of precipitations and abundant mosquitoes populations.

Many cases of the human dirofilarial disease were reported from several European countries some located into Romania environs: Hungary, ${ }^{8}$ Serbia, ${ }^{9}$ Bulgaria, ${ }^{10}$ Moldova, ${ }^{11}$ Ukraine, ${ }^{12}$ Russia ${ }^{13,14}$ as well as in Italy ${ }^{15,16}$ and France. ${ }^{17}$ The seroprevalence studies conducted in both humans and dogs have proved the wide European exposure at D. repens.

As in our case, the human D. repens disease is a slight infection, only the eye involvement rises more simptomatology. The presence of the isolated nodules may be a challenging diagnosis issue, especially on some body areas such as brest, head or neck since the likelihood of a malignancy or a granulomatous disorder misdiagnosis. Raccurt has indicated that $50 \%$ of dirofilarial superficial nodules are on the head, then conjunctiva and orbit $(29,4 \%) .{ }^{18}$

Diagnosis of human subcutaneous dirofilariasis rely on the morphology of the biopsy material (specimen), the polymerase chain reaction technique being a controversial alternative. ${ }^{19}$ Specific serology was negative for Toxocara spp. and Trichinella spiralis as most appropiate serologic assays available at time, than no crossreactivity was disclosed between this three tissular nematodes.

\section{Conclusion}

This case suggests that dirofilariasis should be included in the differential diagnosis of the human nodular disorders at any age and a worried concern from public health outlook. As a vector-borne disease, dirofilariasis is a serious threat for the human health adding this parasitic disease to other notorious infections with a hyperendemic profile in Romania such as cystic echinococcosis or toxocariasis, both by digestive route of transmission, but all three with similar animal reservoir.

\section{Acknowledgments}

None.

\section{Conflicts of interest}

Authors declare that there is no conflicts of interest.

\section{References}

1. Dinulescu Gh, Niculescu Al. Clinical Veterinary Parasitology; 1960. 
2. Olteanu Gh. Dirofilariasis in man and animals in Romania. Parassitologia, 1996, 38:360. Pampilione S; Rivasi F. Human dirofilariasis due to Dirofilaria (Nochtiella) repens: an update of world literature from 1995 to 2000. Parassitologia. 2000;42:231-254.

3. Gherman I. Dictionary of Parasitology. Ed.Stiintifica; 1990.

4. Popescu I, Tudose I, Racz P, et al. Human Dirofilaria repens infection in Romania; a case report. Case Rep Infect Dis. 2012;2012:472976.

5. Arbune M, Dobre M. Dirofilariasis-emergent human parasitosis in Romania. Acta Parasitol. 2015;60(3):485-487.

6. Panaitescu D, Preda A, Baiu O, et al. Four cases of human filariasis due to Setaria labiatopapillosa found in Bucharest, Romania. Rom Arch Microbiol Immunol. 1999;58(2):203-207.

7. Ionica AM, Matei IA, Mircean V, et al. Current surveys on the prevalence and distribution of Dirofilaria spp and Acanthocheilonema reconditum infectiuons in dogs in Romania. Parasitol Res. 2015;114(3):975-982.

8. Ponyai K, Wikonkal N, Bottlik G, et al. Dirofilaria repens infection case in Hungary: a case report. J Dtsch dermatol Ges. 2006;4(12):1051-1053.

9. Kristic M, Gabrielli S, Ignjatovic M, et al. An appraisal of canine and human cases reveals an endemic status of dirofilariosis in parts of Serbia. Mol Cell Probes. 2017;31:37-41.

10. Harizanov RN, Jordanova DP, Bikpv IS. Some aspects of the epidemiology, clinical manifestations and diagnosis of human dirofilariasis caused by Dirofilaria repens. Parasitol Res. 2014;113(4):1571-1579.

11. Ciuca L,Simon F, Rinaldi L, et al. Seroepidemiological survey of human exposure to Dirofilaria spp. In Romania and Moldova. Acta Trop. 2018;187:169-174.
12. Salamatin R, Pavlikovska TM, Sagach OS, et al. Human dirofilariasis due to Dirofilaria repens in Ukraina, en emergent zoonosis: epidemiological report of 1465 cases. Acta Parasitol. 2013;58(4):592-598.

13. Kramer L, Kartashev V, Grandi G, et al. Human subcutaneous dirofilariasis, Russia. Emerg Infect Dis. 2007;13(1):150-152.

14. Ermakova LA, Nagorny SA, Pshenichnaya NY, et al. Clinical and laboratory features of human dirofilariasis in Russia. ID cases. 2017;9:112-115.

15. Pampiglione S, Rivasi F, Angeli G, et al. Dirofilariasis due to D.repens in Italy, an emergent zoonosis: Report of 60 new cases. Histopathology. 2001;38(4):344-354.

16. Genchi C, Kramer L. Subcutaneous dirofilariosis (Dirofilaria repens): an infection spreading throughout the old world. Parasit Vectors. 2017;10(Suppl 2):517.

17. de Boysson H, Duhamel C, Heuze-Lecornu L, et al. Dirofilariose humaine: un nouvau cas francais a Dirofilaria repens. Rev Med Interne. 2012;33(4):e19-21.

18. Raccurt CP. Dirofilariasis: an emerging and underestimated zoonosis in France. Med Trop (Mars). 1999;59(4):389-400.

19. Manzzocchi S, Venco L, Piseddu E, et al. Positive PCR alone should not be considerd sufficient to establish Dirofilaria repens as the cause of subcutaneous nodular lesions in the absence of a clear cytologic picture. Vet Clin Pathol. 2017;46(3):389-390. 